\title{
CAMBIO CLIMÁTICO Y CIUDADES: CONSIDERACIONES PARA ENTENDER LAS VULNERABILIDADES
}

\author{
CLIMATE CHANGE AND CITIES: \\ CONSIDERATIONS TO UNDERSTAND VULNERABILITIES
}

\author{
Bryan Vargas-Vargas \\ (iD) orcid.org/0000-0002-1324-4421 \\ Universidad Estatal a Distancia \\ Costa Rica \\ bvargas@uned.ac.cr
}

\begin{abstract}
It is a proposal of criteria for the identification/prioritization of vulnerabilities to climate change and how sensitivity, exposure and adaptation capacity are expressed in the territory or city. It is taken as a case study, a neighborhood inserted in an industrial zone in the canton of Curridabat, San José, Costa Rica. Methodologically, it is a literature review on climate vulnerability contrasted with data from Costa Rica about climate change and the conditions of the context. The main conclusion is the need to insert the capacity for adaptation as indissoluble to read climate vulnerability.
\end{abstract}

Keywords: human activities effects, climate change, soil degradation, urban areas, environmental indicators, vulnerabilities.

\begin{abstract}
Resumen
El artículo propone criterios de identificación/priorización de vulnerabilidades ante el cambio climático y cómo se expresan la sensibilidad, la exposición y la capacidad de adaptación en el territorio o la ciudad. Se toma como caso de estudio un asentamiento barrial inserto en una zona industrial en el cantón de Curridabat, San José, Costa Rica. Metodológicamente es una revisión de literatura sobre la vulnerabilidad climática contrastada con datos propios de cambio climático costarricense y las condiciones del contexto. Como principal conclusión está la necesidad de inserción de la capacidad de adaptación como indisoluble para hacer lectura de la vulnerabilidad climática.
\end{abstract}

Palabras clave: efectos de las actividades humanas, cambio climático, degradación de suelos, zona urbana, indicadores ambientales, vulnerabilidad. 


\section{Introducción}

A partir de la teoría del Cambio Climático (CC) hay una construcción particular sobre cómo entender la vulnerabilidad climática en una triada indisoluble compuesta por: a) la exposición, es decir, "los factores típicos de exposición [que] incluyen la temperatura, la precipitación, la evapotranspiración y el balance hídrico climático, así como los eventos extremos, como fuertes lluvias y la sequía meteorológica”; b) la sensibilidad, entendida como el grado de afectación debido a todas condiciones intrínsecas a un lugar o asentamiento, en otras palabras: "la sensibilidad determina el grado en que un sistema está adverso o benéficamente afectado por la exposición a un cambio climático dado" y c) la capacidad de adaptación: las posibilidades materiales, culturales, económicas y políticas de anticipar o asimilar lo que determina la exposición, entiéndase: "ajuste de los sistemas naturales o humanos en respuesta a los estímulos climáticos reales o previstos, o a sus efectos, que modera el daño o explota oportunidades benéficas. La adaptación es un proceso y no un resultado" (Fritzsche et al., 2016: 18-21).

En esta lógica hay una relación importante entre éstas y dependen recíprocamente; por ejemplo, entre menos capacidad de adaptación, el impacto potencial será más perjudicial, por lo que se presentarán algunas consideraciones sobre el CC como fenómeno global y las diferenciaciones de mitigación y adaptación como problema local.

Algunas reflexiones sobre el riesgo son diferentes en términos operativos, pero se completarían, ya que de fondo hay lecturas compartidas, en tanto hay derivaciones e inseguridades no deseadas, globales, incuestionables e incalculables, producto de la sociedad moderna industrial y burguesa, como pueden ser los problemas medioambientales o las crisis y desigualdades económicas, muy cercano en este sentido a lo que Beck sostiene: "El progreso puede convertirse en autodestrucción. La modernización reflexiva significa un cambio en la sociedad industrial que se produce de forma subrep- ticia y no planeada" (Beck, citado por Alfie Cohen y Méndez B., 2000: 181).

Sobre la complejidad del fenómeno pretendido, Mussetta et al. han expresado que "sin comprender las causas profundas que explican los procesos de vulnerabilidad es imposible que la comunidad científica brinde herramientas para la toma de decisión política" (2017: 143). Autoras como López-García y Manzano (2016) y Sandoval et al. (2014) nos exponen también la importancia de criterios socioambientales en el análisis de la vulnerabilidad y las percepciones ante los mismos.

Tres conclusiones son fundamentales en este sentido: a) hay dificultad metodológica en la construcción de datos de vulnerabilidad (García-Benítez y Adame-Martínez, 2017), b) "la capacidad adaptativa es dinámica en cada territorio y depende de una gestión que interrelacione aspectos económicos, naturales, institucionales, tecnológicos y de organización social" (Valencia Rojas et al., 2014) y c) las soluciones a largo plazo se basan en la capacidad de construir sociedades más justas, equitativas, con sentido de solidaridad y activando la participación y corresponsabilidad social (Soares y Sandoval-Ayala, 2016).

En este sentido, el presente artículo es una revisión documental que propone un conjunto de criterios que deben ser considerados para evaluar la vulnerabilidad climática de un centro de población en el contexto de las zonas urbanas, tomando como referencia un escenario costarricense.

Para esto es importante referirse propiamente a condiciones de cambio climático verificables en Costa Rica y entender la vulnerabilidad en sus tres dimensiones. La figura 1 resume cómo se comprende la vulnerabilidad: 


\section{Figura 1}

Esquema de vulnerabilidad climática

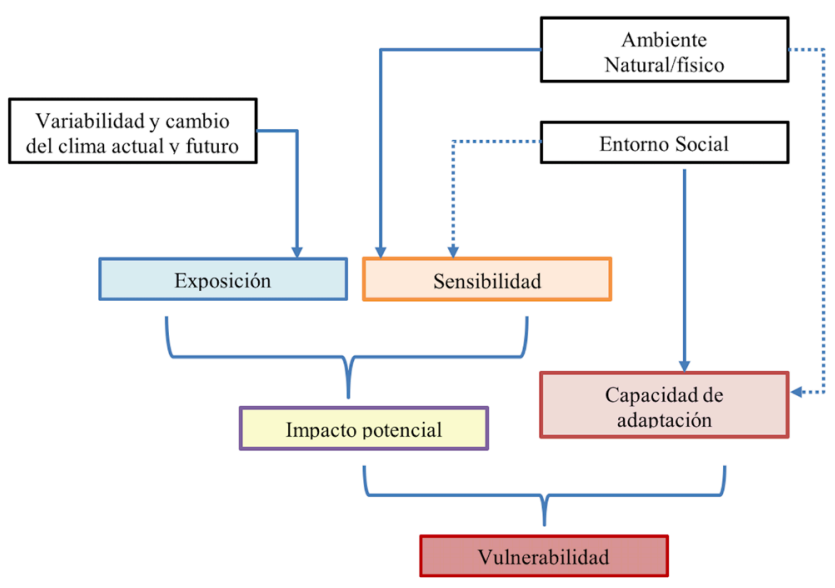

Fuente: Fritzsche et al., 2016: 20.

Esta comprensión sobre la vulnerabilidad ante el Cambio Climático es más cercana al enfoque ecosistémico para comprender la sociedad y lo que nos interesa en este caso, un enfoque ecosistémico de la ciudad. Rosales-Pérez retoma esta perspectiva desde Allmendinger y lo explica de la siguiente forma:

[...] han surgido enfoques emergentes en el campo disciplinario del urbanismo, los cuales se han vinculado con los valores epistemológicos de nuevos paradigmas, disciplinas y formas de conocimiento, y han incorporado una visión holística de totalidad y complejidad, imprescindible para el análisis, el diseño, la gestión y la administración de las ciudades del siglo XXI. Esto se traduce en la inclusión de las nociones de equidad, democracia, construcción de consenso, justicia y ética ambiental en el campo disciplinario del urbanismo (2018: 12).

Sobre cómo se entiende la vulnerabilidad urbana ante el cambio climático seguidamente se desarrolla el estudio de caso.

\section{Marco teórico}

\section{El antropoceno, territorio latinoamericano y cambio climático}

El orden de este primer subtítulo presume que hay un hilo entre la actividad humana sobre la naturaleza, la configuración de territorios y el devenir de consecuencias climáticas, aunque el término antropoceno es un concepto en construcción (Trischler, 2017); en lo que sí hay constancia es que se hace referencia a un momento diferente de cambios en la biosfera en un corto plazo, en comparación con otros periodos y que se atribuyen a la actividad humana. Por ejemplo, debido a la utilización de combustibles fósiles se ha producido un aumento de la temperatura planetaria:

\section{Si la proporción actual de combustibles fósi- les se mantiene y la demanda energética casi se duplica para 2050, las emisiones supera- rán enormemente la cantidad de carbono que se puede emitir si se ha de limitar el aumento medio de temperatura a nivel mundial a $2^{\circ} \mathrm{C}$. El nivel de emisiones tendría consecuencias climáticas desastrosas para el planeta (Foster y Elzinga, 2021).}

Quisiéramos rastrear este supuesto -actividad antropocéntrica-territorios-clima- de forma histórica y epistemológica, como lógica de un proceso de modernización, que establece relaciones del ser humano sobre la naturaleza y el sentido económico que se expresa en los tres procesos "concurrentes y simultáneos de la modernización" a saber: "la dinámica, la morfología y el marco existencial" para el caso latinoamericano, según explica Baraona Cockerell:

La dinámica en tanto una forma específica de historicidad, que resulta del advenimiento del capitalismo, su desarrollo, y los conflictos que en torno a este proceso se tejen de forma constante. Morfología, en tanto el proceso de expansión geográfica del capitalismo (globalización desde su aparición) y que conduce hacia una sola sociedad y economía planetaria. Marco existencial y en tanto el proceso de colonización espiritual del ser humano, para condicionar la subjetividad y colectividades a un tipo de racionalidad económica, que atenta contra la racionalidad de muchos otros aspectos existenciales fundamentales de la humanidad (Baraona Cockerell, 2011: 49-50). 
Lo que supone lo anterior son tres condiciones impuestas: a) el desarrollo del capitalismo como único y total basado en la extracción de riquezas y excedentes del trabajo sometido, b) la inserción en una economía mundo, pero diferenciada entre conquistadores y conquistados, c) el sentido económico existencial. Por tanto, la relación actividad antropocéntrica-territorios-clima- está permeada por un sentido modernizador, desigual y economicista. El siguiente esquema resume esta relación:

Figura 2

\section{Diagrama teórico de la dinámica, la morfología, el marco existencial y su vínculo con el antropoceno}
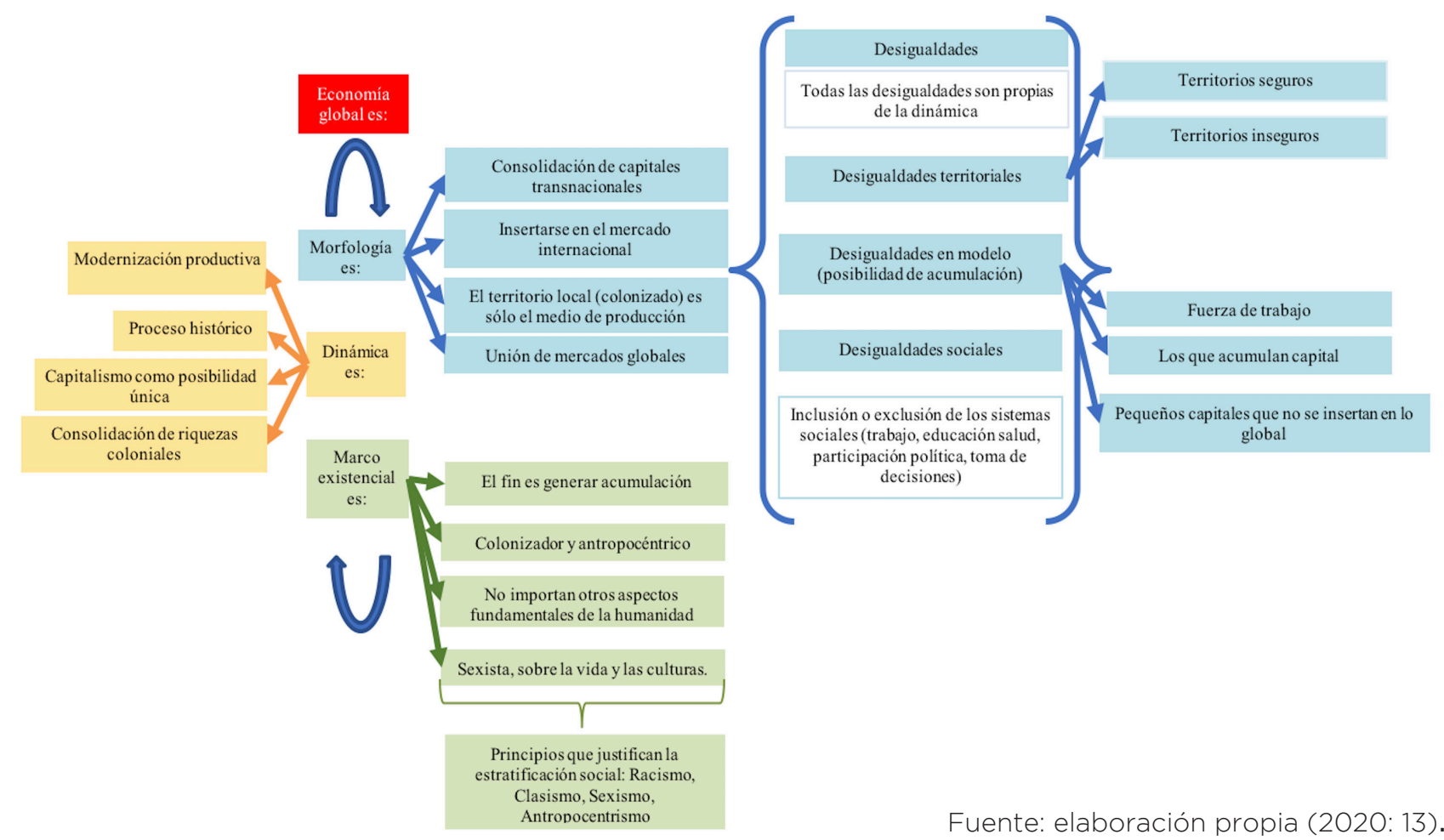

De fondo también hay que señalar la comprensión ahistórica de la América conquistada, metafóricamente como una "canasta de recursos" y a la vez un "capital natural”. Neil Brenner (2017) señala por tanto que las ciudades no deben ser vistas únicamente como forma y demografía; lo mismo señala Svampa (2016) cuando ratifica la premisa del pensamiento productivista y economicista latinoamericano. En la formación de los territorios y urbes latinoamericanas se arrastra entonces una desigualdad social y una vocación hacia el crecimiento económico, que pasa por mercantilizar, extraer y privatizar, claro está que los recursos medioambientales formarán parte del extractivismo modernizador.

¿Qué se extrae de las ciudades? No hay que perder el señalamiento inicial de este trabajo respecto a que "el progreso puede convertirse en autodestrucción subrepticia y no planeada" (Beck, citado por Alfie Cohen y Méndez, 2000: 181). No sólo se trata de qué se extrae, sino también qué deja la producción y quién asume por tanto esa externalidad; en este sentido hay que incluir todas las consecuencias de la urbanización, por ejemplo: desde la emisión de desechos de las industrias hasta la emisión de gases de los sistemas de transporte. Respondiendo a la pregunta ¿Qué se extrae de las ciudades?, a modo de ejemplo Costa Rica tiene una relación particular que merece mayor análisis en términos de costos de su produc- 
ción con la industria tecnológica, "ubicando a Intel en uno de los mayores consumidores industriales de agua y energía” (López Corrales, 2005: 321).

\section{Costa Rica y Cambio Climático}

Consecuente con el apartado anterior, no es extraña la dualidad territorial y urbana costarricense; por un lado, somos ejemplo de protección y conservación de los recursos naturales, pero a la vez somos depredadores de otros sectores, por ejemplo, en el monocultivo de piña que ha sido adverso en térmi- nos medioambientales y sociales, pero que se explica por la intención de permanecer en la economía mundial, sin que esto implique una repartición de la riqueza producida. De fondo pueden existir muchas causas, desde lo endebles que ha sido las instituciones vinculadas con el territorio hasta una lógica imperante en generación de recursos económicos aprovechando la falta de regulación. A modo de ejemplo, se presenta el vigesimosegundo informe Estado de la Nación en desarrollo humano sostenible (2016), titulado "Expansión por omisión":

\section{Cuadro 1 \\ Hectáreas de monocultivos en los cantones de Los Chiles, Upala y Guatuso (Huetar Norte-Norte), Costa Rica. 2004-2015}

\begin{tabular}{|c|c|c|c|c|c|}
\hline \multirow{4}{*}{$\begin{array}{l}\text { Producto: } \\
\text { Piña }\end{array}$} & Año 1984 & \multirow{4}{*}{$\begin{array}{c}\text { Producto: } \\
\text { Naranja }\end{array}$} & Año 1984 & \multirow{4}{*}{$\begin{array}{c}\text { Producto: } \\
\text { Banano }\end{array}$} & Año 1984 \\
\hline & $2.474,1$ ha & & $2.764,9$ ha & & 32.316.1 ha \\
\hline & Año 2014 & & Año 2014 & & Año 2014 \\
\hline & $37.659,9$ ha & & $19.595,7$ ha & & 51.758,1 ha \\
\hline \multirow{4}{*}{$\begin{array}{c}\text { Producto: } \\
\text { Palma Aceitera }\end{array}$} & Año 1984 & \multirow{4}{*}{$\begin{array}{c}\text { Producto: } \\
\text { Caña de azúcar }\end{array}$} & Año 1984 & \multirow{4}{*}{$\begin{array}{c}\text { Producto: } \\
\text { Café }\end{array}$} & Año 1984 \\
\hline & $16.830,2$ ha & & $47.286,2$ ha & & 89.881 ha \\
\hline & Año 2014 & & Año 2014 & & Año 2014 \\
\hline & $66.419,8$ ha & & 65.062 ha & & $84.133,1$ ha \\
\hline
\end{tabular}

Fuente: Programa Estado Nación (2016: 11).

Tres puntos respecto al dato anterior: a) se considera un error fraccionar el territorio como si no hubiese conexiones y consecuencias entre la ciudad y la ruralidad, b) esta ampliación de áreas productivas implica una reducción de zonas boscosas o incluso protegidas (Araya, 2017) y c) que en medio de la producción persistente crecen ciudades-enclaves; algunas de estas costeras tienen sus particularidades con respecto a afectaciones climáticas.

Ahora bien, sobre el principal núcleo de urbanización en el centro del territorio, la Universidad de Costa Rica (Blanco Picado, 2017) ha demostrado que la ciudad de San José -donde se enmarca el lugar que se desea problematizar- de 1960 a 2015 tiene una tendencia al aumento de la temperatura de 0.09 grados centígrados por década y la temperatura máxima ha subido 0.4 en 55 años. Se señala que esto puede deberse a causas incluso naturales pero que el problema es la transformación de los suelos hacia un uso urbano que ahora es incapaz de filtrar los fenómenos atmosféricos.

En su Política Nacional de Costa Rica de Adaptación al Cambio Climático, el Gobierno de la República de Costa Rica (2018) señala que desde la década de los noventa se han elaborado escenarios, exposiciones y vulnerabilidades ante un evento hidrometeoro extremo. Para el contexto de San José hay una alerta principalmente sobre las posibles afectaciones en la infraestructura pública (vial, energética, agua potable y acceso a servicios). Si bien hay un avance en la dimensión de la adaptación, mediante la construcción de datos, en la aceptación de 
protocolos internacionales y elaboración de política propia, lo cierto es que parece haber dificultades para concretar las medidas o en algunos casos pueden no ser suficientes. La Contraloría General de la República señala:

Es impostergable avanzar en la recuperación de la infraestructura nacional con criterios de blindaje climático, que considere las prioridades en función de su impacto en los ámbitos social, económico y ambiental, y la resiliencia de la obra pública en el largo plazo para enfrentar los embates del cambio climático (Gobierno de la República de Costa Rica, 2018: 33).

Hay otras exposiciones que ya han sido proyectadas y verificables en el caso de Costa Rica. En el primer caso se conocen las proyecciones del aumento de los mares y las afectaciones en los asentamientos costeros y en el segundo caso por la constancia en el aumento de las temperaturas hay una relación con la presencia de vectores infecciosos (Andrade-Ochoa et al., 2017).

\section{El contexto urbano costarricense}

Parte de las problemáticas históricas del Estado costarricense es su incapacidad de una planificación del territorio y la conurbación que conocemos como Gran Área Metropolitana (GAM) no escapa a la desregulación. La GAM concentra en aproximadamente 4\% del territorio nacional a más de la mitad de la población y es el principal núcleo de actividades económicas, instituciones y de servicios. Explica la Cruz Roja Costarricense lo siguiente:

Este crecimiento poblacional desordenado propicia a cierta parte de la población (sobre todo la de escasos recursos) a ubicarse sobre terrenos con niveles de riesgo elevados, como por ejemplo antiguos rellenos, laderas de fuerte pendiente, terrazas y cortes mal diseñados, zonas de protección fluvial, entre otros (Bonilla, et al., 2006). La falta de planificación y ordenamiento territorial, donde han aumentado los núcleos poblacionales y el desarrollo industrial desordenado, asociado a una defi- ciente gestión municipal, permite la invasión de asentamiento humano a estas zonas de riesgo (Retana et al., citados por Guzmán Brenes, 2009: 26).

Los procesos particulares de urbanización y la imposibilidad de ordenamiento territorial no sólo son negativos en el riesgo al que se exponen ciertas poblaciones, sino que además sobre el fenómeno del cambio climático hay otras expresiones que aportan datos significativos (negativos), como la emisión de $\mathrm{CO}_{2}$ por parte de la flota vehicular (privado y transporte público concesionado), que representa $70 \%$ de las emisiones, la pérdida de zonas boscosas producto de la extensión horizontal de la ciudad, degradación de los suelos y del recurso hídrico producto de los monocultivos, entre otras realidades. El Programa Estado Nación afirmó:

en la Gran Área Metropolitana de los $700 \mathrm{~km}^{2}$ de terrenos de aptitud forestal y cubiertos con bosques, han sido objeto de deforestación más del 60\%, provocando un desbalance ambiental y una significativa cadena de impactos que involucran temas como la afectación de ecosistemas, daños a corredores biológicos, impactos severos en el paisaje y desertificación (Programa Estado Nación, 2010: 23).

Ante esto no es extraño entonces que se manifiesten escenarios de vulnerabilidad climática, como ya han señalado entidades internacionales en el tema y expertos, donde probablemente se afectaran aquellos grupos con menos posibilidades de adaptación; esto implica desde el conocimiento/ comprensión de los fenómenos climáticos hasta las posibilidades materiales para resolverlos.

Ahora bien, de lo que sí se tiene evidencia suficiente en esta Gran Área Metropolitana son las consecuencias de fenómenos hidrometeorológicos y que se podrían agravar y ser más frecuentes, como lo son lluvias torrenciales o tormentas, encharcamientos, desbordamiento de ríos y arroyos, inundaciones, deslizamientos de terreno, despren- 
dimientos de rocas, incremento de la temperatura y la sensación térmica de calor en la población, islas o archipiélagos.

En términos generales son fenómenos homogéneos para toda la población, pero como la sociedad no es uniforme evidentemente hay grupos que están más vulnerables que otros; ante esto apunta Salas Murillo sobre el área metropolitana:

La investigación reportó que el desarrollo urbano de las comunidades presenta vulnerabilidades debido a que se construye en terrenos no aptos, además hay un mal manejo de las aguas servidas y pluviales. Por esa razón, Produs recomienda detener la constante invasión que hacen las personas de los cauces y márgenes de los ríos (2015: 36).

Es por lo anterior que se toma el escenario de la zona industrial de Curridabat a modo de ejemplo, para evaluar la vulnerabilidad de este sector en sus tres dimensiones (sensibilidad, exposición y capacidad de aportación).

\section{Estudio de caso (Curridabat, San José, Costa Rica) ${ }^{1}$}

Aunque se selecciona este lugar para la construcción de indicadores, esto no quiere decir que sea el único asentamiento en la GAM en esa situación, hay una gran cantidad de asentamientos informales ${ }^{2}$ o precarios como se les conoce típicamente en Costa Rica.

En el diagnóstico de amenazas naturales elaborado por la Comisión Nacional de

\footnotetext{
1 El levantamiento y análisis completo del lugar está detallado en Vargas-Vargas et al. (2015).

2 En Costa Rica se ha denominado "asentamiento informal" o "precario" a los conjuntos de viviendas en malas condiciones materiales, desprovistos de servicios urbanos (calles, alcantarillado, agua, servicio eléctrico y otros) y una característica muchas veces implícita es alguna condición peligrosa, como al margen de un río, zona inundable, sitio de deslizamientos. Cada uno de estos asentamientos merecería un análisis sólo para nombrarlo de forma correcta, por ejemplo: algunos se han ido consolidando en la ciudad, dándosele servicios o el derecho del suelo, por lo que el término informal ya no tendría mucho sentido.
}

Emergencias de Costa Rica (2021: 1), se señalan las siguientes sobre el sector de $\mathrm{Cu}$ rridabat:

Estos ríos y quebradas los más importantes han disminuido el período de recurrencia de inundaciones a un año, y algunos a períodos menores, lo anterior por causa de la ocupación de las planicies de inundación, y el desarrollo urbano en forma desordenada y sin ninguna planificación. Así mismo el lanzado de desechos sólidos a los cauces de los mismos, redundando lo anterior en la reducción de la capacidad de la sección hidráulica, lo que provoca el desbordamiento de ríos y quebradas. Situación que se ha generado por los serios problemas de viviendas cercanas a los ríos en el cantón de Curridabat (Comisión Nacional de Emergencias de Costa Rica, 2021: 1).

En el sitio hay que distinguir dos áreas inmediatas, pero con características distintas, como lo son el Barrio María Auxiliadora y el Barrio Nuevo, ambos circundados por la zona de uso industrial. El primer barrio (María Auxiliadora) es reconocido como tal por el gobierno local y las condiciones de infraestructura, vivienda y sociales son más favorables que con respecto a Barrio Nuevo.

Este último (asentamiento informal) es el más expuesto a diversas condiciones, por ubicarse en las laderas del río y por mal estado de las viviendas y en general del sitio; en $2011^{3}$ estaba compuesto por: Niños y Niñas (O-4 años), 97 absolutos, 10.94\%; Niños y Niñas (5-12 años), 160 absolutos, 18.04\%; Adolescentes (13-17 años), 109 absolutos, 12.29\%; Jóvenes (18-35 años), 318 absolutos, 35.85\%; Personas Adultas (36-64 años), 186 absolutos, 20.97\%; Personas Adultas Mayores (más de 65 años), 15 absolutos, 1.69\%. Hay que agregar un importante número de población inmigrante (principalmente de origen nicaragüense), con diversos problemas de salud, un bajo clima educativo y bajos ingresos, ámbitos que a su vez se complejizan por la condición migratoria (Paniagua Arguedas et al., 2012: 10-13).

$\overline{3 \text { Año del último }}$ censo de población en Costa Rica 
De los diagnósticos ya existentes, hay amenazas bien caracterizadas, a saber:

a) actividad deslizamiento de tierra, sobre todo hacia los sectores aledaños de los ríos Tiribí y María Aguilar, b) actividad volcánica y c) deslizamientos, siendo los sectores más propensos a inestabilidad de terrenos, son aquellos aledaños a los ríos María Aguilar y Tiribí y hacia los terrenos inclinados de Lomas San Antonio (al sur de Curridabat) (Municipalidad de Curridabat, 2019: 5).

A esta condición de amenaza en los ríos se puede sumar el índice de calidad del agua de los ríos y quebradas del cantón Curridabat, el cual señala que sólo un $3 \%$ de los ríos estudiados no presenta contaminación ${ }^{4}$ (Municipalidad de Curridabat, 2019: 5)

Hay una sensibilidad mayor de la población en tugurio ${ }^{5}$ al margen del río, en comparación con el restante asentamiento más adentrado en el tejido urbano. Esta zona industrial tiene varias exposiciones en su configuración; primero: puede ser aire contaminado que inmediatamente llega a los vecinos; segundo: las laderas inestables al margen del río María Aguilar.

Históricamente no ha habido capacidad de adaptación (éste es el tema a desarrollar en el siguiente apartado, la metodología, particularmente en la columna 4 del cuadro 2), ya que el asentamiento ha sufrido deslizamientos en el periodo de lluvia, que se repite cada año, además de haber sido afectado en una ocasión por un incendio significativo.

Ante esto, desde una revisión documental y teórica seguidamente se pretende crear una matriz de criterios, variables e indicadores que permitan la identificación y priorización de vulnerabilidades, dando un énfasis a los siguientes criterios: a) Físico ambien-

4 Los restantes porcentajes son los siguientes (Índice Holandés del análisis físico-químico): $37 \%$ de los sitios analizados: contaminación incipiente, 30\% de los sitios muestreados: contaminación moderada, $20 \%$ de los puntos estudiados: contaminación severa y $10 \%$ de los puntos muestreados: contaminación muy severa. 5 Nombre utilizado en Costa Rica para los asentamientos en condiciones de pobreza. tal, es decir, condiciones de tipo biofísicas ambientales intrínsecas de los ecosistemas que pueden representar una exposición al asentamiento o viceversa; b) Físico espacial, entiéndase condiciones de tipo materiales propias de la estructura urbana, incluyendo estado de los suelos y la vivienda; c) Sociales, entiéndase condiciones propias de la población y calidad de vida urbana; d) Productivos económicos, entiéndase condiciones propias de la economía existente y la calidad de vida, y e) Político e institucionales, entiéndase condiciones producto de la legislación vinculante e institucionalidad competente.

\section{Metodología}

En el cuadro 2 se presenta en primer lugar la exposición, seguido de su indicador; posteriormente se detallan las sensibilidades que pueden agravar la exposición y la capacidad de adaptación se traza como acciones o medidas que deben realizarse para atenuar la vulnerabilidad y sensibilidad a las condiciones que de existir o no agravan la exposición.

Se hace el mismo proceso con los cinco criterios antes mencionados; se tiene claro que algunas exposiciones no son producto de la variación climática, pero son consideraciones de contexto que se piensan relacionados con las exposiciones directas y por tanto de considerar y medir.

Ver cuadro completo en Anexo 1. 


\section{Cuadro 2 \\ Criterios, variables e indicadores de vulnerabilidad urbana para el sector Curridabat, Costa Rica (2019)}

\begin{tabular}{|c|c|c|c|}
\hline Exposición & Indicador & Sensibilidad particular & Capacidad o medida de adaptación \\
\hline 1.1. Aumento de la temperatura. & $\begin{array}{l}\text { Incremento gradual de la } \\
\text { temperatura. }\end{array}$ & $\begin{array}{l}\text { Presencia de todos los } \\
\text { segmentos de la } \\
\text { población y } \\
\text { enfermedades que } \\
\text { pueden estar asociadas. }\end{array}$ & $\begin{array}{l}\text { - Las viviendas deben tener } \\
\text { materiales y diseño adecuados para } \\
\text { la contención del calor. } \\
\text { - Crear datos longitudinales (en } \\
\text { diferentes momentos para medir la } \\
\text { evolución). }\end{array}$ \\
\hline $\begin{array}{l}\text { 1.2. Susceptibilidad de las viviendas a } \\
\text { inundaciones o deslizamientos del } \\
\text { terreno. Degradación por } \\
\text { desplazamiento (Cotler et al., 2007: 7). }\end{array}$ & $\begin{array}{l}\text { Registro de } \\
\text { deslizamientos. }\end{array}$ & $\begin{array}{l}\text { Presencia de varios } \\
\text { sectores de la población } \\
\text { y sus diversas } \\
\text { enfermedades } \\
\text { asociadas. }\end{array}$ & $\begin{array}{l}{ }^{*} \text { Evacuar puntos donde exista } \\
\text { registro de inundaciones. } \\
{ }^{*} \text { Priorizar la calidad de vivienda y la } \\
\text { reubicación en casos extremos. } \\
{ }^{*} \text { Crear datos longitudinales. }\end{array}$ \\
\hline $\begin{array}{l}\text { 1.3. Susceptibilidad de las viviendas a } \\
\text { inundaciones o deslizamientos del } \\
\text { terreno. } \\
\text { Degradación por deterioro interno } \\
\text { (Cotler et al., 2007: 7). }\end{array}$ & $\begin{array}{l}\text { * Coeficiente de } \\
\text { permeabilidad del suelo } \\
\text { y las diversas cualidades } \\
\text { necesarias del suelo para } \\
\text { soportar el uso urbano. } \\
\text { * Registros de aumento } \\
\text { o salida del rio "María } \\
\text { Aguilar" }\end{array}$ & $\begin{array}{l}\text { * Mal estado de las } \\
\text { viviendas. } \\
{ }^{*} \text { Viviendas sin cumplir } \\
\text { reglamentos de } \\
\text { construcción. }\end{array}$ & $\begin{array}{l}{ }^{*} \text { Evacuar puntos donde exista } \\
\text { registro de inundaciones. } \\
{ }^{*} \text { Priorizar la calidad de vivienda y la } \\
\text { reubicación en casos extremos. } \\
{ }^{*} \text { Crear datos longitudinales. } \\
{ }^{*} \text { Construir planes de contingencia y } \\
\text { atlas de riesgos. }\end{array}$ \\
\hline $\begin{array}{l}\text { 1.4. Susceptibilidad de las viviendas a } \\
\text { inundaciones o deslizamientos del } \\
\text { terreno. } \\
\text { Degradación por deterioro interno } \\
\text { (Cotler et al., 2007: 7). }\end{array}$ & $\begin{array}{l}\text { Medición de cobertura } \\
\text { vegetal. }\end{array}$ & $\begin{array}{l}\text { Viviendas ya afectadas } \\
\text { en otros momentos. }\end{array}$ & $\begin{array}{l}\text { Evacuar puntos donde exista registro } \\
\text { de deslizamientos, compactación u } \\
\text { otro indicador que incremente una } \\
\text { exposición. }\end{array}$ \\
\hline $\begin{array}{l}\text { 1.5. Fenómenos hidrometeorológicos } \\
\text { (lluvias extremas). }\end{array}$ & $\begin{array}{l}\text { Proyecciones y cálculos } \\
\text { de metros cúbicos de } \\
\text { lluvia extrema. }\end{array}$ & $\begin{array}{l}\text { * Mal estado de las } \\
\text { viviendas. } \\
\text { * Inexistencia de } \\
\text { infraestructura urbana } \\
\text { (alcantarillado, agua } \\
\text { potable). }\end{array}$ & $\begin{array}{l}\text { * Dimensionamiento correcto de las } \\
\text { tuberías. } \\
{ }^{*} \text { Desarrollar una estrategia de } \\
\text { atención de emergencias. } \\
{ }^{*} \text { Crear datos longitudinales. } \\
{ }^{*} \text { Diseñar y construir la } \\
\text { infraestructura en caso de que no } \\
\text { exista. }\end{array}$ \\
\hline $\begin{array}{l}\text { 1.6. Aumento de enfermedades } \\
\text { provocadas por el mosquito Aedes } \\
\text { aegypti. }\end{array}$ & $\begin{array}{l}\text { Número de nuevos } \\
\text { casos de virus. }\end{array}$ & $\begin{array}{l}\text { * Población con alguna } \\
\text { enfermedad } \\
\text { permanente. } \\
\text { * Población sin } \\
\text { seguridad social. }\end{array}$ & $\begin{array}{l}\text { * Planes de fumigación, } \\
\text { principalmente en el periodo de } \\
\text { lluvia. } \\
\text { * Desarrollar planes educativos para } \\
\text { la prevención de formación de } \\
\text { criaderos de zancudos. } \\
{ }^{*} \text { Crear datos longitudinales. }\end{array}$ \\
\hline 1.7. Fallas geológicas* & Mapa geológico. & $\begin{array}{l}\text { * Mal estado de las } \\
\text { viviendas. } \\
{ }^{*} \text { Viviendas sin cumplir } \\
\text { reglamentos de } \\
\text { construcción. }\end{array}$ & $\begin{array}{l}\text { Evacuar puntos donde exista } \\
\text { presencia de fallas; de mantenerse en } \\
\text { el sitio, se deben cumplir los } \\
\text { requerimientos técnicos. }\end{array}$ \\
\hline 1.8. Actividad volcánica* & $\begin{array}{l}\text { Mapa de ubicación de } \\
\text { volcanes y anillo de } \\
\text { contención. }\end{array}$ & $\begin{array}{l}\text { Poblaciones con } \\
\text { enfermedades } \\
\text { respiratorias y alergias. }\end{array}$ & $\begin{array}{l}{ }^{*} \text { Evacuar puntos donde hay } \\
\text { presencia de fallas. } \\
{ }^{*} \text { No otorgar permisos donde exista } \\
\text { un riesgo por actividad volcánica. }\end{array}$ \\
\hline 1.9. Olas de calor. & $\begin{array}{l}\text { Medición permanente de } \\
\text { la temperatura. }\end{array}$ & $\begin{array}{l}\text { Población sin acceso a } \\
\text { seguridad social. }\end{array}$ & $\begin{array}{l}\text { - Contar con una respuesta de } \\
\text { contingencia. } \\
\text { - Crear datos longitudinales }\end{array}$ \\
\hline
\end{tabular}

Fuente: elaboración propia, 2019 (Ver Anexo 1). 


\section{Resultados}

La naturaleza del presente artículo no permite obtener los resultados de la matriz de vulnerabilidad propuesta, ya que es una herramienta mínima que se propone para posteriores análisis, pero sobre el sitio en cuestión sí ofreció una complejidad importante y una suma de fenómenos, los cuales deben resolverse en las dimensiones naturales, sociales, económicas y formales de la ciudad y de organización interinstitucional.

Se considera que en general para Costa Rica y su proceso de urbanización, la labor por crear una política pública o una metodología sobre cambio climático debe ir más allá de pretender cumplir compromisos internacionales y procurar una acción para la prevención de desastres socio- ambientales, hacer inversiones físicas eficientes y construir capacidades sociales que respondan a las condiciones climáticas, tomar acciones para reducir los gases de efecto invernadero propios de la urbanización y lo más importante: resguardar la vida de las personas, sobre todo de las más vulnerables.

Este escenario de la vida en sociedad como lo es la urbe se concatena en el caso costarricense aproximadamente más del $60 \%$ de su población, que se moviliza de un punto a otro del área metropolitana con el fin de cumplir con funciones principales como empleo y educación o abastecerse de los servicios comerciales e instituciones que se concentran en la ciudad. La descripción anterior no es menor: en el $4 \%$ del territorio nacional (2.044 km aproximadamente, que representa el área metropolitana) se concentra la mayor parte de su población y la mayor parte de los empleos. A pesar que desde 1968 tenemos la Ley de Planificación Urbana Núm. 4240 (SCIJ, 1968), esto no ha sido sinónimo de orden o planeamiento; por el contrario, la ciudad creció de forma horizontal, desordenada, sacrificando zonas boscosas y protegidas y con fuertes problemas de movilidad urbana (transporte).

Por lo anterior, las actividades económicas y la población concentrada en un territorio estrecho requieren de un soporte en el sentido amplio con la finalidad de mejorar las condiciones de vida de la población. Es por esto que atender las urbes y las condiciones climáticas se configuran en un problema público, que afecta a la mayor parte de la población costarricense y necesitan de una atención inmediata.

Lo primero que hay que posicionar al respecto es que se entienda el Cambio Climático y la urbanización como un problema público por las implicaciones que tiene, la movilidad urbana en términos del estrés generado, la pérdida de vínculos familiares por los largos desplazamientos, las enfermedades respiratorias asociadas a la emisión de gases, entre otras consecuencias, pero también porque debe resolver la gestión del riesgo y asegurar los bienes, el bienestar y la vida de los ciudadanos.

El Cambio Climático y la urbanización deben considerarse con base en las relaciones sistémicas entre las dinámicas de la población, las formas productivas y el equilibrio necesario con el medio natural; sólo así se puede dar una respuesta coherente y acorde. Sobre la metodología desarrollada y la revisión de fuentes, se considera que pueden nutrirse en campo, contrastando con experiencias de investigación y con el aporte de diversas áreas del conocimiento que se vuelven necesarias para completar un esquema/matriz como el propuesto. La inserción de la variabilidad climática y la vulnerabilidad como se entendió en este caso obliga primero a buscar una comprensión de la mutabilidad misma e implica consideraciones para la toma de decisiones territoriales de un análisis más relacional de las condiciones y de largo plazo.

\section{Discusión}

Hay una cuestión de fondo que puede explicarse con las condiciones vistas en el lugar de análisis, como lo es el derecho a la ciudad. En entrevista en 2017 en el marco de la conferencia Hábitat, Joan Subirats, experto en políticas públicas, señaló que el derecho a la ciudad es un concepto para articular las múltiples relaciones que ocurren en las 
ciudades y que en esencia hace referencia a tres contenidos: a) acceso a derechos básicos, b) ambiental, salud y físico y c) democratización de la toma de decisiones (Hernández y Rivera, 2017: 106).

Bajo este paradigma de derecho a la ciudad hay discusiones fundamentales para el bienestar social de quienes residen en la ciudad y para un modelo de ciudad. Uno de estos temas es el acceso a la vivienda como derecho y no como un producto para el canje en el mercado y especulativo como lo es en este momento. Subirats es preciso al señalar que quizá ha sido de las reuniones más importantes, ya que tiene que asumir cuestiones de fondo como el cambio climático, tecnológico y de economía global. Y hace una fuerte crítica a principios asumidos sin ninguna criticidad como el Smart Cities, que describe como la inserción tecnológica en la ciudad, pero sin cuestionar las problemáticas estructurales y estructurantes de las mismas (Hernández y Rivera, 2017: 107).

\section{Fotografías 1 y 2 Barrio Nuevo de Curridabat, Costa Rica}

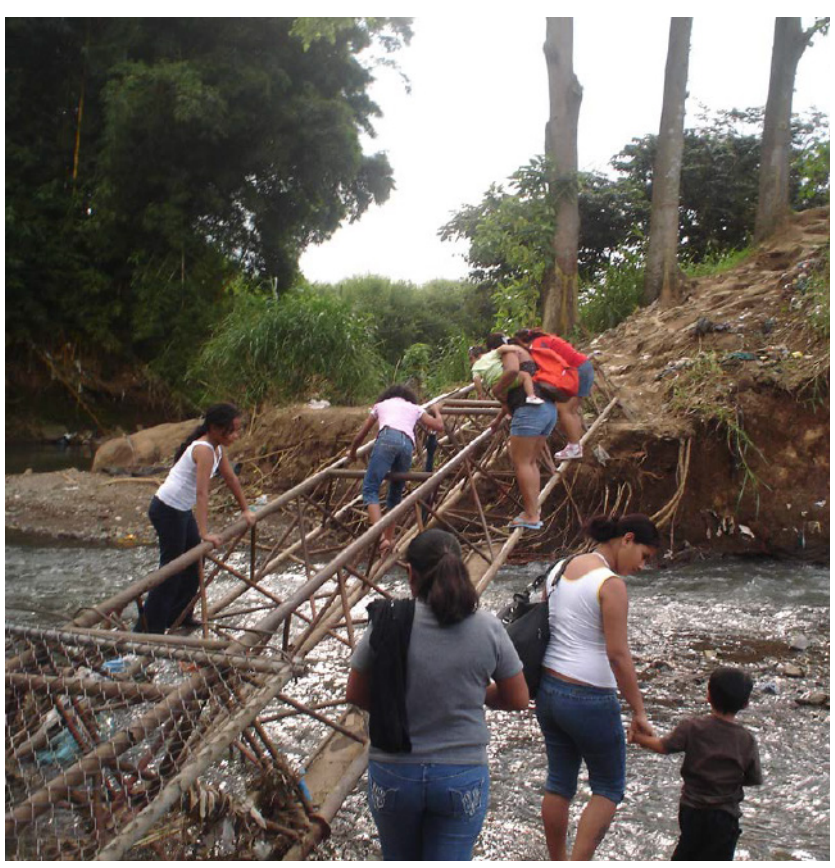

Fuente: Paniagua Arguedas (2014: 4 y 6).

En este sentido, el derecho a la ciudad puede hacer referencia a esa justicia urbana de la cual nuestro escenario visto en las fotografías 1 y 2 no es ejemplo; por el contrario: muestra las desigualdades y vulnerabilidades que se deben atender de forma holística y urgente. Como hemos venido describiendo, la vulnerabilidad es la relación de condiciones, por lo que cuestionar de fondo los cambios climático, tecnológico y de economía global es una necesidad y de no hacerse persistirá la respuesta diferenciada a los fenómenos que aquejan a la ciudad o a los territorios.

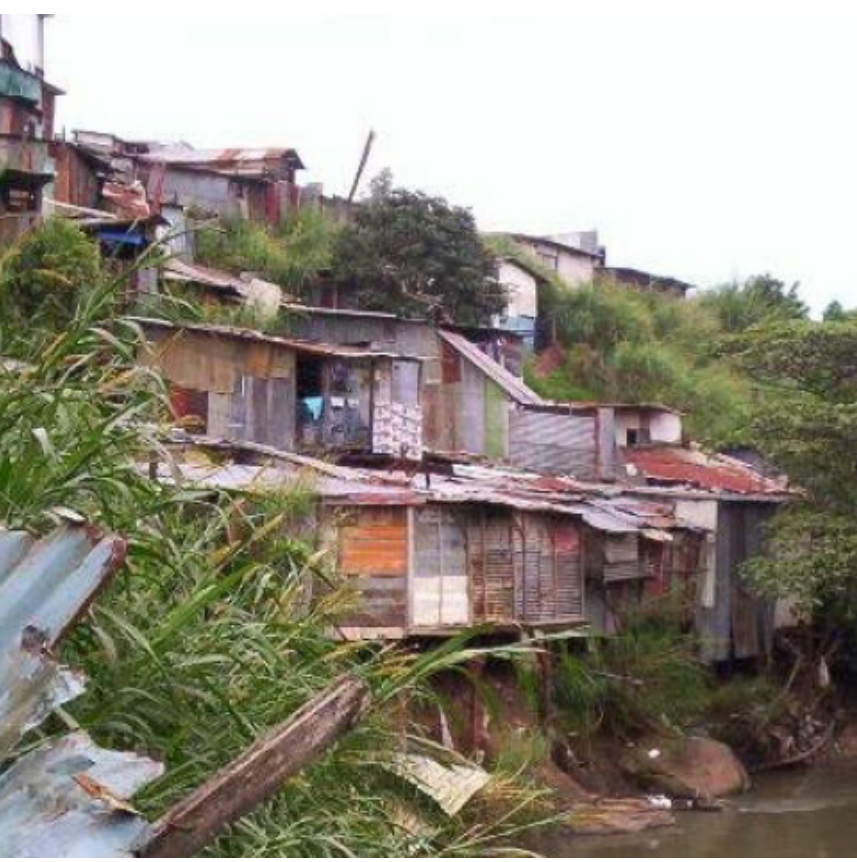

La capacidad de adaptación es la posibilidad de prever las nuevas condiciones en un sentido amplio, es decir, involucra desde la concientización sobre el fenómeno y el conocimiento del mismo, políticas globales o locales, hasta el acondicionamiento material de las infraestructuras.

Por otro lado, hay que afirmar que la vulnerabilidad ante el Cambio Climático responde siempre al contexto, por lo que en este ejercicio hay una preocupación por hacer lectura de la yuxtaposición de capas o condiciones que configuran la ciudad o en este caso la zona industrial de Curridabat. 
Tanto complejo es el cambio climático como complicado el adaptarse a las nuevas condiciones, para esto sin duda la comprensión del CC debe ser transversal en políticas e instituciones y procesos educativos a cualquier nivel, e incluso debería ser columna vertebral para algunas áreas como por ejemplo el planeamiento territorial y urbano, el manejo de los recursos naturales y en la industria agropecuaria.

Debe ser transversal en cada espacio de estudio, atender las condiciones no sólo de clase social que pueden ser más evidentes para adaptarse o no al Cambio Climático, e incorporar otras condiciones estructurales y estructurantes como la cultura y el género, así como la interseccionalidad entre éstas.

En una economía dependiente, desigual y siempre en crisis es consecuente que existan expresiones muy amplias de la vulnerabilidad, preocupa en buena parte que no se piense afrontar holísticamente el CC; por ejemplo, Costa Rica importa desde hace ya mucho tiempo buena parte de arroz y frijol, que son base de la dieta de su población, por lo que pensar el abastecimiento alimentario y su vínculo con las nuevas condiciones climáticas debería ser una ocupación, que de momento parece no ser prioritario. Evidentemente afrontar el cambio climático implica una ruptura general, no se puede sólo pensar en crecimiento económico, sin algún grado de justicia económica, social y medioambiental.

Para concluir hay una idea que interesa retomar, el nosotros planteado por Welzer (2010), quien critica la elaboración del nosotros como causa y solución del cambio climático, cuando la historia y alguna ciencia nos han demostrado quiénes son responsables de las afectaciones medioambientales y lo más importante: que no hay igualdad en las acciones climáticas para adaptarse y mitigar; por tanto, es necesario un cambio estructural de la sociedad moderna, por lo que la labor para las ciudades latinoamericanas implica nuestro propio desarrollo y revisar lo hecho.

\section{Anexo 1 \\ Criterios, variables e indicadores de vulnerabilidad urbana para el sector Curridabat, Costa Rica (2019)}

\begin{tabular}{|c|c|c|c|c|}
\hline \multicolumn{5}{|c|}{$\begin{array}{c}\text { MATRIZ DE IDENTIFICACIÓN DE VULNERABILIDAD PARA LA ZONA INDUSTRIAL CURRIDABAT Y BARRIO NUEVO DE } \\
\text { CURRIDABAT, } 2019\end{array}$} \\
\hline \multirow{4}{*}{$\begin{array}{l}\text { 1. CRITERIO } \\
\text { FÍSICO } \\
\text { AMBIENTAL }\end{array}$} & EXPOSICIÓN & INDICADOR & $\begin{array}{l}\text { SENSIBILIDAD } \\
\text { PARTICULAR }\end{array}$ & CAPACIDAD O MEDIDA DE ADAPTACIÓN \\
\hline & $\begin{array}{l}\text { 1.1. Aumento de } \\
\text { la temperatura }\end{array}$ & $\begin{array}{l}\text { Incremento } \\
\text { gradual de la } \\
\text { temperatura }\end{array}$ & $\begin{array}{l}\text { Presencia de todos } \\
\text { los segmentos de } \\
\text { la población y } \\
\text { enfermedades que } \\
\text { pueden estar } \\
\text { asociadas. }\end{array}$ & $\begin{array}{l}\text { * Las viviendas deben tener materiales y diseño } \\
\text { adecuados para la contención del calor. } \\
\text { * Crear datos longitudinales (en diferentes } \\
\text { momentos para medir la evolución). }\end{array}$ \\
\hline & $\begin{array}{l}\text { 1.2. } \\
\text { Susceptibilidad } \\
\text { de las viviendas } \\
\text { a inundaciones o } \\
\text { deslizamientos } \\
\text { del terreno. } \\
\text { Degradación por } \\
\text { desplazamiento } \\
\text { (Cotler et al., } \\
\text { 2007: } 7 \text { ). }\end{array}$ & $\begin{array}{l}\text { Registro de } \\
\text { deslizamientos }\end{array}$ & $\begin{array}{l}\text { Presencia de } \\
\text { varios sectores de } \\
\text { la población y sus } \\
\text { diversas } \\
\text { enfermedades } \\
\text { asociadas. }\end{array}$ & $\begin{array}{l}* \text { Evacuar puntos donde exista registro de } \\
\text { inundaciones. } \\
{ }^{*} \text { Priorizar la calidad de vivienda y la reubicación } \\
\text { en casos extremos. } \\
{ }^{*} \text { Crear datos longitudinales. }\end{array}$ \\
\hline & $\begin{array}{l}\text { 1.3. } \\
\text { Susceptibilidad } \\
\text { de las viviendas } \\
\text { a inundaciones o } \\
\text { deslizamientos } \\
\text { del terreno. } \\
\text { Degradación por } \\
\text { deterioro interno } \\
\text { (Cotler et al., } \\
\text { 2007: 7). }\end{array}$ & $\begin{array}{l}{ }^{*} \text { Coeficiente de } \\
\text { permeabilidad } \\
\text { del suelo y } \\
\text { diversas } \\
\text { cualidades } \\
\text { necesarias del } \\
\text { suelo para } \\
\text { soportar el uso } \\
\text { urbano. } \\
{ }^{*} \text { Registros de } \\
\text { aumento o salida } \\
\text { del río María } \\
\text { Aguilar. }\end{array}$ & $\begin{array}{l}* \text { Mal estado de } \\
\text { las viviendas. } \\
{ }^{*} \text { Viviendas sin } \\
\text { cumplir } \\
\text { reglamentos de } \\
\text { construcción. }\end{array}$ & $\begin{array}{l}\text { * Evacuar puntos donde exista registro de } \\
\text { inundaciones. } \\
{ }^{*} \text { Priorizar la calidad de vivienda y la reubicación } \\
\text { en casos extremos. } \\
{ }^{*} \text { Crear datos longitudinales. } \\
{ }^{*} \text { Construir planes de contingencia y atlas de } \\
\text { riesgos. }\end{array}$ \\
\hline
\end{tabular}




\section{Anexo 1 Continuación}

1. CRITERIO
FÍSICO
AMBIENTAL

\begin{tabular}{|c|c|c|c|}
\hline EXPOSICIÓN & INDICADOR & $\begin{array}{l}\text { SENSIBILIDAD } \\
\text { PARTICULAR }\end{array}$ & CAPACIDAD O MEDIDA DE ADAPTACIÓN \\
\hline $\begin{array}{l}1.4 . \\
\text { Susceptibilidad } \\
\text { de las viviendas } \\
\text { a inundaciones o } \\
\text { deslizamientos } \\
\text { del terreno. } \\
\text { Degradación por } \\
\text { deterioro interno } \\
\text { (Cotler et al., } \\
2007: 7 \text { ). }\end{array}$ & $\begin{array}{l}\text { Medición de } \\
\text { cobertura } \\
\text { vegetal. }\end{array}$ & $\begin{array}{l}\text { Viviendas ya } \\
\text { afectadas en otros } \\
\text { momentos. }\end{array}$ & $\begin{array}{l}\text { Evacuar puntos donde exista registro de } \\
\text { deslizamientos, compactación u otro indicador } \\
\text { que incremente una exposición. }\end{array}$ \\
\hline $\begin{array}{l}\text { 1.5. Fenómenos } \\
\text { hidrometeorológ } \\
\text { icos (Iluvias } \\
\text { extremas). }\end{array}$ & $\begin{array}{l}\text { Proyecciones y } \\
\text { cálculos de } \\
\text { metros cúbicos } \\
\text { de lluvia } \\
\text { extrema. }\end{array}$ & $\begin{array}{l}\text { * Mal estado de las } \\
\text { viviendas. } \\
\text { * Inexistencia de } \\
\text { infraestructura } \\
\text { urbana } \\
\text { (alcantarillado, } \\
\text { agua potable). }\end{array}$ & $\begin{array}{l}\text { * Dimensionamiento correcto de las tuberías. } \\
\text { * Desarrollar una estrategia de atención de } \\
\text { emergencias. } \\
\text { * Crear datos longitudinales. } \\
\text { * Diseñar y construir la infraestructura en el caso } \\
\text { de que no exista. }\end{array}$ \\
\hline $\begin{array}{l}\text { 1.6. Aumento de } \\
\text { enfermedades } \\
\text { del mosquito } \\
\text { Aedes aegypti. }\end{array}$ & $\begin{array}{l}\text { Número de } \\
\text { nuevos casos de } \\
\text { virus. }\end{array}$ & $\begin{array}{l}\text { * Población con } \\
\text { alguna } \\
\text { enfermedad } \\
\text { permanente. } \\
\text { * Población sin } \\
\text { seguridad social. }\end{array}$ & $\begin{array}{l}\text { * Planes de fumigación, principalmente en el } \\
\text { periodo de lluvia. } \\
\text { * Desarrollar planes educativos para la } \\
\text { prevención de formación de criaderos de } \\
\text { zancudos. } \\
{ }^{*} \text { Crear datos longitudinales. }\end{array}$ \\
\hline $\begin{array}{l}\text { 1.7. Fallas } \\
\text { geológicas* }\end{array}$ & Mapa geológico. & $\begin{array}{l}\text { * Mal estado de las } \\
\text { viviendas. } \\
{ }^{*} \text { Viviendas sin } \\
\text { cumplir } \\
\text { reglamentos de } \\
\text { construcción. }\end{array}$ & $\begin{array}{l}\text { Evacuar puntos donde exista presencia de fallas; } \\
\text { de mantenerse en el sitio, se deben cumplir los } \\
\text { requerimientos técnicos. }\end{array}$ \\
\hline $\begin{array}{l}\text { 1.8. Actividad } \\
\text { volcánica* }\end{array}$ & $\begin{array}{l}\text { Mapa de } \\
\text { ubicación de } \\
\text { volcanes y anillo } \\
\text { de contención. }\end{array}$ & $\begin{array}{l}\text { Poblaciones con } \\
\text { enfermedades } \\
\text { respiratorias y } \\
\text { alergias. }\end{array}$ & $\begin{array}{l}\text { * Evacuar puntos donde hay presencia de fallas. } \\
\text { * No otorgar permisos donde exista un riesgo } \\
\text { por la actividad volcánica. }\end{array}$ \\
\hline 1.9. Olas de calor. & $\begin{array}{l}\text { Incremento } \\
\text { gradual de la } \\
\text { temperatura. }\end{array}$ & $\begin{array}{l}\text { Población sin } \\
\text { acceso a } \\
\text { seguridad social. }\end{array}$ & $\begin{array}{l}\text { - Contar con un programa de contingencia. } \\
\text { - Crear datos longitudinales. }\end{array}$ \\
\hline $\begin{array}{l}\text { 1.10. Pérdida de } \\
\text { flora y fauna. } \\
\text { Degradación por } \\
\text { deterioro } \\
\text { interno. }\end{array}$ & $\begin{array}{l}\text { Número de } \\
\text { diversidad } \\
\text { natural existente. }\end{array}$ & $\begin{array}{l}\text { No hay registros } \\
\text { previos de este } \\
\text { indicador. }\end{array}$ & $\begin{array}{l}\text { - Registrar los recursos endémicos. } \\
\text { - Registrar los recursos endémicos que puedan } \\
\text { ayudar a procesos regenerativos del suelo u } \\
\text { otro. }\end{array}$ \\
\hline $\begin{array}{l}\text { 1.11. Calidad del } \\
\text { agua. }\end{array}$ & $\begin{array}{l}\text { * Cantidad y } \\
\text { calidad de agua } \\
\text { potable. } \\
\text { * Calidad de } \\
\text { agua de ríos y } \\
\text { quebradas. }\end{array}$ & $\begin{array}{l}\text { Mala calidad de } \\
\text { agua en sitio. }\end{array}$ & $\begin{array}{l}\text { * Conservación y protección de los acuíferos. } \\
\text { * Gestión conjunta de las aguas superficiales y } \\
\text { subterráneas. } \\
\text { * Conservar, mantener o recuperar los } \\
\text { ecosistemas de humedales. } \\
\text { * Entender la dependencia del agua y los riesgos } \\
\text { climáticos asociados. } \\
\text { * Reducir la exposición al riesgo y mejorar la } \\
\text { resiliencia en los ámbitos urbano y rural. } \\
\text { * Infraestructuras resistentes al cambio climático } \\
\text { (ONU-Agua, 2019: 16-18). }\end{array}$ \\
\hline $\begin{array}{l}\text { 2.1. Cercanía de } \\
\text { zona industrial. }\end{array}$ & $\begin{array}{l}\text { * Mapa de usos } \\
\text { de suelo. } \\
{ }^{*} \text { Medición de } \\
\text { gases de efecto } \\
\text { invernadero. } \\
\text { * Datos de } \\
\text { enfermedades } \\
\text { asociadas. }\end{array}$ & $\begin{array}{l}\text { *Población con } \\
\text { enfermedades } \\
\text { respiratorias o } \\
\text { alergias. } \\
{ }^{*} \text { Deforestación o } \\
\text { pérdida de } \\
\text { cobertura vegetal. }\end{array}$ & $\begin{array}{l}\text { Realizar una planificación estratégica y funcional } \\
\text { de los usos urbanos. }\end{array}$ \\
\hline $\begin{array}{l}\text { 2.2. Gases } \\
\text { contaminantes } \\
\text { del proceso } \\
\text { industrial. }\end{array}$ & $\begin{array}{l}\text { * Indicadores de } \\
\text { contaminación } \\
\text { ambiental. } \\
\text { * Datos de } \\
\text { enfermedades } \\
\text { asociadas. }\end{array}$ & $\begin{array}{l}\text { * Población con } \\
\text { enfermedades } \\
\text { respiratorias o } \\
\text { alergias. } \\
\text { * Deforestación o } \\
\text { pérdida de } \\
\text { cobertura vegetal. }\end{array}$ & $\begin{array}{l}\text { * Realizar una planificación estratégica y } \\
\text { funcional de los usos urbanos. } \\
{ }^{*} \text { Crear datos longitudinales. }\end{array}$ \\
\hline $\begin{array}{l}\text { 2.3. Ausencia de } \\
\text { infraestructura } \\
\text { básica (agua } \\
\text { potable, } \\
\text { electricidad, } \\
\text { alcantarillado)* }\end{array}$ & $\begin{array}{l}\text { Mapa de } \\
\text { disponibilidad de } \\
\text { servicios. }\end{array}$ & $\begin{array}{l}\text { * Población sin } \\
\text { acceso al agua } \\
\text { potable. } \\
\text { * Sectores } \\
\text { urbanos sin } \\
\text { infraestructura } \\
\text { básica. } \\
\text { * Presencia de } \\
\text { población adulta } \\
\text { mayor. } \\
\text { * Presencia de } \\
\text { población con } \\
\text { alguna } \\
\text { discapacidad. }\end{array}$ & $\begin{array}{l}\text { Procurar una ciudad planificada, ordenada y con } \\
\text { equipamiento social acorde con la población. }\end{array}$ \\
\hline
\end{tabular}




\begin{tabular}{|c|c|c|c|c|}
\hline $\begin{array}{l}\text { Anexo } 1 \\
\text { Continuación }\end{array}$ & EXPOSICIÓN & INDICADOR & $\begin{array}{l}\text { SENSIBILIDAD } \\
\text { PARTICULAR }\end{array}$ & CAPACIDAD O MEDIDA DE ADAPTACIÓN \\
\hline \multirow[b]{2}{*}{$\begin{array}{l}\text { 2. CRITERIO } \\
\text { FÍSICO ESPACIAL }\end{array}$} & $\begin{array}{l}\text { 2.4. Sin rutas de } \\
\text { evacuación* }\end{array}$ & & $\begin{array}{l}\text { * Presencia de } \\
\text { población adulta } \\
\text { mayor. } \\
\text { * Presencia de } \\
\text { población con } \\
\text { alguna } \\
\text { discapacidad. }\end{array}$ & Crear planes de atención de emergencias. \\
\hline & $\begin{array}{l}\text { 2.5. Sin manejo } \\
\text { de desechos. }\end{array}$ & $\begin{array}{l}\text { * Indicadores de } \\
\text { contaminación } \\
\text { ambiental. } \\
\text { * Medición de } \\
\text { gases de efecto } \\
\text { invernadero. } \\
\text { * Datos de } \\
\text { enfermedades } \\
\text { asociadas. }\end{array}$ & $\begin{array}{l}\text { * Sectores } \\
\text { urbanos sin } \\
\text { infraestructura } \\
\text { básica. } \\
\text { * Sectores } \\
\text { urbanos sin } \\
\text { manejos de } \\
\text { desechos (basura, } \\
\text { gases y aguas } \\
\text { residuales). }\end{array}$ & $\begin{array}{l}\text { * Crear planes de manejo de desechos. } \\
\text { * Procurar una ciudad planificada, ordenada y } \\
\text { con equipamiento social acorde con la } \\
\text { población. }\end{array}$ \\
\hline \multirow{8}{*}{$\begin{array}{l}\text { 3. CRITERIO } \\
\text { SOCIAL }\end{array}$} & $\begin{array}{l}\text { 3.1. Familias sin } \\
\text { los necesarios } \\
\text { ingresos } \\
\text { económicos* }\end{array}$ & $\begin{array}{l}\text { Datos } \\
\text { socioeconómicos } \\
\text {. }\end{array}$ & $\begin{array}{l}\text { Familias bajo la } \\
\text { línea de pobreza o } \\
\text { pobreza extrema. }\end{array}$ & Crear planes de fomento del empleo estable. \\
\hline & $\begin{array}{l}\text { 3.2. Mal estado } \\
\text { de las } \\
\text { edificaciones* }\end{array}$ & $\begin{array}{l}\text { Evaluación del } \\
\text { inmueble. }\end{array}$ & $\begin{array}{l}\text { * Familias sin } \\
\text { condiciones } \\
\text { económicas para } \\
\text { construir bajo } \\
\text { criterios técnicos. } \\
\text { * Políticas } \\
\text { burocráticas de } \\
\text { vivienda y sin } \\
\text { relación con un } \\
\text { modelo de ciudad. }\end{array}$ & $\begin{array}{l}\text { Evacuar viviendas en mal estado o ya afectadas } \\
\text { en otros momentos. }\end{array}$ \\
\hline & $\begin{array}{l}\text { 3.3. Alta } \\
\text { densidad de } \\
\text { población* }\end{array}$ & $\begin{array}{l}\text { Densidad de } \\
\text { población. }\end{array}$ & $\begin{array}{l}\text { Concentración de } \\
\text { población alta. }\end{array}$ & $\begin{array}{l}\text { Procurar una densidad de población acorde con } \\
\text { las condiciones metabólicas del lugar. }\end{array}$ \\
\hline & $\begin{array}{l}\text { 3.4. Tenencia } \\
\text { irregular de la } \\
\text { tierra* }\end{array}$ & $\begin{array}{l}\text { Títulos de } \\
\text { propiedad. }\end{array}$ & $\begin{array}{l}\text { * Familias en } \\
\text { territorios sin } \\
\text { adecuado } \\
\text { fraccionamiento y } \\
\text { equipamiento } \\
\text { social. } \\
\text { * Toma ilegal de } \\
\text { terrenos. }\end{array}$ & $\begin{array}{l}\text { Formalizar la tenencia de la tierra bajo criterios } \\
\text { urbanísticos y ambientales. }\end{array}$ \\
\hline & $\begin{array}{l}\text { 3.5. Crecimiento } \\
\text { de población* }\end{array}$ & $\begin{array}{l}\text { Número de } \\
\text { población y } \\
\text { características } \\
\text { demográficas } \\
\text { (género). }\end{array}$ & & Proyecciones de población. \\
\hline & $\begin{array}{l}\text { 3.6. Distancia de } \\
\text { centros de } \\
\text { atención de } \\
\text { salud* }\end{array}$ & $\begin{array}{l}\text { Mapeo de } \\
\text { equipamiento } \\
\text { social. }\end{array}$ & $\begin{array}{l}\text { Presencia de } \\
\text { población con } \\
\text { alguna } \\
\text { discapacidad. }\end{array}$ & Establecer equipamiento social necesario. \\
\hline & $\begin{array}{l}\text { 3.7. Sin } \\
\text { participación } \\
\text { comunitaria o } \\
\text { grupos } \\
\text { organizados* }\end{array}$ & $\begin{array}{l}\text { * Número de } \\
\text { grupos } \\
\text { organizados. } \\
{ }^{*} \text { Número de } \\
\text { nuevas } \\
\text { demandas } \\
\text { sociales. }\end{array}$ & $\begin{array}{l}\text { Población con } \\
\text { dificultades para } \\
\text { elaborar } \\
\text { demandas ante la } \\
\text { institucionalidad. }\end{array}$ & $\begin{array}{l}\text { Promover estrategias de participación } \\
\text { comunitaria. }\end{array}$ \\
\hline & $\begin{array}{l}3.8 . \\
\text { Desconocimient } \\
\text { o y/o negación } \\
\text { de la exposición. }\end{array}$ & $\begin{array}{l}{ }^{*} \text { Grupos focales } \\
\text { para comprender } \\
\text { valores } \\
\text { culturales. } \\
{ }^{*} \text { Datos de } \\
\text { niveles } \\
\text { educativos. }\end{array}$ & $\begin{array}{l}\text { * Bajo nivel } \\
\text { educativo. }\end{array}$ & Promover estrategias de comprensión cultural. \\
\hline \multirow{2}{*}{$\begin{array}{l}\text { 4. CRITERIO } \\
\text { PRODUCTIVO } \\
\text { ECONÓMICO }\end{array}$} & $\begin{array}{l}\text { 4.1. Dependencia } \\
\text { de población } \\
\text { vulnerables* }\end{array}$ & $\begin{array}{l}\text { Población } \\
\text { económicamente } \\
\text { activa. }\end{array}$ & $\begin{array}{l}\text { * Presencia de } \\
\text { población adulta } \\
\text { mayor. } \\
{ }^{*} \text { Presencia de } \\
\text { población con } \\
\text { alguna } \\
\text { discapacidad. }\end{array}$ & Crear planes de fomento del empleo estable. \\
\hline & $\begin{array}{l}\text { 4.2. Población } \\
\text { desempleada* }\end{array}$ & $\begin{array}{l}\text { * Población } \\
\text { económicamente } \\
\text { activa } \\
\text { *Población } \\
\text { desempleada }\end{array}$ & $\begin{array}{l}\text { Población sin } \\
\text { ingresos } \\
\text { económicos. }\end{array}$ & Crear planes de fomento del empleo estable. \\
\hline
\end{tabular}




\begin{tabular}{|c|c|c|c|c|}
\hline $\begin{array}{l}\text { Anexo } 1 \\
\text { Continuación }\end{array}$ & EXPOSICIÓN & INDICADOR & $\begin{array}{l}\text { SENSIBILIDAD } \\
\text { PARTICULAR }\end{array}$ & CAPACIDAD O MEDIDA DE ADAPTACIÓN \\
\hline \multirow[b]{2}{*}{$\begin{array}{l}\text { 4. CRITERIO } \\
\text { PRODUCTIVO } \\
\text { ECONÓMICO }\end{array}$} & $\begin{array}{l}\text { 4.3. Desempleo } \\
\text { generalizado** }\end{array}$ & & $\begin{array}{l}\text { Población sin } \\
\text { ingresos } \\
\text { económicos. }\end{array}$ & Crear planes de fomento del empleo estable. \\
\hline & $\begin{array}{l}\text { 4.4. Población } \\
\text { con beneficio de } \\
\text { transferencia } \\
\text { condicionada de } \\
\text { alguna entidad } \\
\text { de gobierno* }\end{array}$ & $\begin{array}{l}\text { Número de } \\
\text { beneficiarios. }\end{array}$ & $\begin{array}{l}\text { * Población con } \\
\text { baja escolaridad. } \\
* \text { Familias bajo la } \\
\text { línea de pobreza o } \\
\text { pobreza extrema. }\end{array}$ & $\begin{array}{l}\text { Crear planes de fomento del empleo estable o } \\
\text { atención integral mediante transferencias } \\
\text { condicionadas. }\end{array}$ \\
\hline \multirow{5}{*}{$\begin{array}{l}\text { 5. CRITERIOS } \\
\text { POLÍTICOS E } \\
\text { INSTITUCIONALES }\end{array}$} & $\begin{array}{l}\text { 5.1. Sin } \\
\text { comprensión de } \\
\text { cambio climático } \\
\text { (gobiernos } \\
\text { locales). }\end{array}$ & $\begin{array}{l}\text { Planes de } \\
\text { gobierno ante el } \\
\text { Cambio } \\
\text { Climático. }\end{array}$ & & $\begin{array}{l}\text { * Construir planes detallados de adaptación al } \\
\text { Cambio Climático. } \\
{ }^{*} \text { Crear datos longitudinales. }\end{array}$ \\
\hline & $\begin{array}{l}\text { 5.2. Sin } \\
\text { comprensión de } \\
\text { cambio climático } \\
\text { (gobiernos } \\
\text { locales). }\end{array}$ & $\begin{array}{l}\text { Planes de } \\
\text { gobierno ante el } \\
\text { Cambio } \\
\text { Climático. }\end{array}$ & $\begin{array}{l}\text { Población sin } \\
\text { capacidad de } \\
\text { adaptación. }\end{array}$ & $\begin{array}{l}* \text { Elaborar planes de atención de emergencias. } \\
{ }^{*} \text { Crear datos longitudinales. }\end{array}$ \\
\hline & $\begin{array}{l}\text { 5.3. Sin leyes, } \\
\text { reglamentos u } \\
\text { otros que } \\
\text { incorporen el } \\
\text { cambio climático } \\
\text { (nacionales o } \\
\text { regionales). }\end{array}$ & $\begin{array}{l}\text { Planes de } \\
\text { gobierno ante el } \\
\text { Cambio } \\
\text { Climático. }\end{array}$ & & $\begin{array}{l}\text { * Actualizar permanentemente datos sobre } \\
\text { cambio climático. } \\
{ }^{*} \text { Crear datos longitudinales. }\end{array}$ \\
\hline & $\begin{array}{l}\text { 5.4. Instituciones } \\
\text { ante el Cambio } \\
\text { Climático. }\end{array}$ & $\begin{array}{l}\text { Instituciones } \\
\text { vinculantes ante } \\
\text { el Cambio } \\
\text { Climático. }\end{array}$ & $\begin{array}{l}\text { *Fragilidad } \\
\text { institucional } \\
\text { (normativa, } \\
\text { económica e } \\
\text { ideológica). } \\
\text { * Fragilidad de los } \\
\text { gobiernos locales } \\
\text { (normativa, } \\
\text { económica e } \\
\text { ideológica). }\end{array}$ & $\begin{array}{l}\text { Determinar instituciones competentes sobre } \\
\text { cambio climático y establecimiento vinculante } \\
\text { de sus decisiones. }\end{array}$ \\
\hline & $\begin{array}{l}\text { 5.5. Omisión } \\
\text { institucional. }\end{array}$ & & $\begin{array}{l}\text { Falta de } \\
\text { presupuesto para } \\
\text { la adaptación y } \\
\text { mitigación. }\end{array}$ & $\begin{array}{l}\text { * Determinar instituciones competentes sobre } \\
\text { cambio climático y establecimiento vinculante } \\
\text { de sus decisiones. } \\
\text { *Establecer recursos específicos para un } \\
\text { desarrollo adaptado a la variabilidad climática. }\end{array}$ \\
\hline
\end{tabular}

Fuente: elaboración propia, 2019.

\section{Fuentes consultadas}

Alfie Cohen, Miriam y Méndez B., Luis $H$. (2000), "La sociedad del riesgo: amenaza y promesa", Sociológica, 15 (43), Ciudad de México, Universidad Autónoma Metropolitana México, pp.173201, <https://acortar.link/IbLIOg>, 11 de septiembre de 2021.

Andrade-Ochoa, Sergio; Chacón-Vargas, Karla Fabiola; Rivera-Chavira, Blanca Estela y Sánchez-Torres, Luvia Enid (2017), "Enfermedades transmitidas por vectores y cambio climático", Investigación y Ciencia, 25 (72), Aguascalientes, Universidad Autónoma de Aguascalientes México, pp.118-128, <https://acortar.link/rKYWG1>, 11 de septiembre de 2021.

Araya, Jorge (2017), "Expansión piñera se comió 5.568 hectáreas de bosque", Se- manario Universidad, 8 de marzo, San José, Universidad de Costa Rica, País, <https://acortar.link/4pOAJo>, 11 de septiembre de 2021.

Baraona Cockerell, Miguel (2011), Diez ensayos críticos, San José, Editorial Germinal.

Blanco Picado, Patricia (2017), "San José se ha calentado en los últimos 50 años", Universidad de Costa Rica, 12 de septiembre, San José, Universidad de Costa Rica, <https://bit.ly/2XHddWa>, 11 de septiembre de 2021.

Bonilla, Esteban; Chaves, Ignacio; Esquivel, Lidier; Madrigal, Julio; Méndez, Johanna y Sjöbohm, Linda (2006), "Causas frecuentes de amenaza y vulnerabilidad: Medidas de prevención y mitigación", San José, Comisión Nacional de Emergencias, <https://bit.ly/3oFWYCj>, 18 de noviembre de 2020. 
Brenner, Neil (2017), Teoría urbana crítica y políticas de escala, Barcelona, Icaria editorial.

Comisión Nacional de Emergencias de Costa Rica (2021), "Amenazas de origen natural cantón de Curridabat", San José, Comisión Nacional de Prevención de Riesgos y Atención de Emergencias de Costa Rica, <https://bit.ly/3iiVZtN>, 14 de septiembre de 2021.

Cotler, Helena; Sotelo, Esthela; Domínguez, Judith; Zorrilla, María; Cortina, Sofía y Quiñones, Leticia (2007), "La conservación de suelos: un asunto de interés público", Gaceta Ecológica, núm. 83, Ciudad de México, Secretaría de Medio Ambiente y Recursos Naturales, pp. 5-71 <https://acortar.link/tawudu>, 13 de septiembre de 2021.

Foster, Scott y Elzinga, David (2021), "El papel de los combustibles fósiles en un sistema energético sostenible", Nueva York, Organización de las Naciones Unidas, <https://bit.ly/3OEEA4k>, 11 de septiembre de 2021.

Fritzsche, Kerstin; Schneiderbauer, Stefan; Bubeck, Philip; Kienberger, Stefan; Buth, Mareike; Zebisch, Marc y Kahlenborn, Walter (2016), El libro de la vulnerabilidad: concepto y lineamientos para la evaluación estandarizada de la vulnerabilidad, Berlín, Ministerio Federal de Cooperación Económica y Desarrollo/ Deutsche Gesellschaft für Internationale Zusammenarbeit (GIZ) GmbH/Adelphi/Eurac research.

García-Benítez, Marcelino y Adame-Martínez, Salvador (2017), "Propuesta metodológica para evaluar la vulnerabilidad por ciclones tropicales en ciudades expuestas", Quivera. Revista de Estudios Territoriales, 19 (2), Toluca, Universidad Autónoma del Estado de México, pp.35-58, <https://bit.ly/39MT43P>, 13 de septiembre de 2021.

Gobierno de la República de Costa Rica (2018), "Política nacional de Costa Rica de adaptación al cambio climático 2018-2030", San José, Programa
ARAUCLIMA, Costa Rica, <https://bit. ly/3zBC5vy>, 14 de septiembre de 2021.

Guzmán Brenes, Luis Augusto (2009), "El Cambio Climático: causas, consecuencias y la reducción de riesgos de desastre de Cruz Roja Costarricense", San José, Federación Internacional de Sociedades de la Cruz Roja y de la Media Luna Roja de Costa Rica, <https:// bit.ly/39vGaqH>, 13 de septiembre de 2021

Hernández, Freddy y Rivera, Jairo (2017), "Gobernanza, ciudades y políticas públicas, una conversación a propósito de Hábitat III y la Nueva Agenda Urbana. Entrevista con Joan Subirats", Mundos Plurales. Revista Latinoamericana de Políticas y Acción Pública, 3 (2), Quito, Facultad Latinoamericana de Ciencias Sociales, pp. 101-13, <https://bit. Iy/2W5NNAT>, 13 de septiembre de 2021

López Corrales, Manuel Francisco (2005), Tratado de Libre Comercio. Estados Unidos, Centroamérica y República Dominicana: Estrategia de tierra arrasada, San José, Universidad Estatal a Distancia.

López-García, Thania Gabriela y Manzano, Mario G. (2016), "Vulnerabilidad climática y situación socioambiental: percepciones en una región semiárida del noreste de México", Madera y Bosques, 22 (2), Veracruz, Instituto de Ecología A.C., pp. 105-117, <https://bit.ly/3CVgos $\mathrm{H}>, 13$ de septiembre de 2021 .

Municipalidad de Curridabat (2019), "Estado de la biodiversidad y los servicios de los ecosistemas en el cantón de Curridabat. Curridabat-Costa Rica", Curridabat, Curridabat ciudad dulce, <https:// bit.ly/3wTtkgD>, 15 de septiembre de 2021.

Mussetta, Paula; Barrientos, María Julia; Acevedo, Erika; Turbay, Sandra y Ocampo, Olga (2017), "Vulnerabilidad al cambio climático: Dificultades en el uso de indicadores en dos cuencas de Colombia y Argentina", Empiria. Revista de Metodología de las Ciencias Sociales, núm. 
36, Madrid, Universidad Nacional de Educación a Distancia, pp. 119-147, <https://bit.ly/3IS1Lzk>, 3 de septiembre de 2021

ONU-AGUA (2019), "Informe de políticas de ONU-AGUA sobre el Cambio Climático y el Agua", Nueva York, Organización de las Naciones Unidas, <https://acortar.link/dcX4L4>, 15 de septiembre de 2021.

Paniagua Arguedas, Laura (2014), "Barrio nuevo lucha por transformarse: Mejoramiento del hábitat popular para los barrios autoconstruidos", REVISTARQUIS, 3 (2), San José, Universidad de Costa Rica, pp. 1-17, <https://bit. ly/3u6s4W4>, 23 septiembre 2021.

Paniagua Arguedas, Laura; Salgado Ramírez, Isaac; Aldi Bolaños, Josué; Marín Díaz, Edgar; Murillo Reynolds, Adriana y Sánchez Hernández, Carolina (2012), "Informe sobre la Comunidad de Barrio Nuevo, Curridabat", Informe de investigación, San Pedro, Escuela de Arquitectura de la Universidad de Costa Rica-Instituto de Investigaciones Sociales <https://acortar.link/emVcZG>, 12 de noviembre 2021.

Programa Estado Nación (2010), "Estado de la Nación en Desarrollo Humano Sostenible. Ordenamiento territorial: implicaciones para el desarrollo humano Costa Rica", San José, Programa Estado Nación.

Programa Estado Nación (2016), "Estado de la Nación en Desarrollo Humano Sostenible. Contribución especial. La expansión por omisión: Territorios piñeros en los cantones Los Chiles, Upala y Guatuso, Costa Rica (2004-2015)", San José, Programa Estado Nación.

Rosales-Pérez, Natalie (2018), "Balance ambiental: una herramienta metodológica para un urbanismo más sustentable", Quivera. Revista de Estudios Territoriales, 20 (1), Toluca, Universidad Autónoma del Estado de México, pp.11-30, <https://bit.ly/3iORgIX>, 3 de septiembre de 2021.
Salas Murillo, Otto (2015), "Produs señala debilidades en infraestructura urbana ante el cambio climático", CRISOL. Revista de Ciencia y Tecnología, núm. 29, San José, Universidad de Costa Rica, pp. 35-36 <https://bit.ly/2XVtO4O>, 4 de septiembre de 2021.

Sandoval, Cecilia; Soares, Denise y Munguía, Ma. Teresa (2014), "Vulnerabilidad social y percepciones asociadas al cambio climático: Una aproximación desde la localidad de Ixil, Yucatán", Sociedad y Ambiente, 1 (5), Campeche, El Colegio de la Frontera Sur, pp. 7-24, <https://bit.ly/2XEtjzl>, 23 de septiembre de 2021.

SCIJ (Sistema Costarricense de Información Jurídica) (1968), "Ley de Planificación Urbana Núm. 4240”, 15/11/1968, San José, Procuraduría General de la República-Sistema Costarricense de Información Jurídica, <https://bit.ly/3oJ1KRo>, 7 de septiembre de 2021.

Soares, Denise y Sandoval-Ayala, Norma Cecilia (2016), "Percepciones sobre vulnerabilidad frente al cambio climático en una comunidad rural de Yucatán", Tecnología y Ciencias del Agua, 7 (4), Jiutepec, Instituto Mexicano de Tecnología del Agua-Coordinación de Comunicación, Participación e Información, pp. 113-128, <https://bit.ly/3o3s20m>, 23 de septiembre de 2021.

Svampa, Maristella (2016), Debates latinoamericanos. Indianismo, desarrollo, dependencia, populismo, Buenos Aires, Edhasa.

Trischler, Helmuth (2017), "El Antropoceno, ¿un concepto geológico o cultural, o ambos?", Desacatos. Revista de Ciencias Sociales, núm. 54, Ciudad de México, Centro de Investigaciones y Estudios Superiores en Antropología Social, pp. 40-57, <https://acortar.link/u37mfR>, 2 de septiembre de 2021.

Valencia Rojas, Mónica Patricia; Figueroa Casas, Apolinar; Ruiz Ordóñez, Diana Marcela; Otero Sarmiento, Juan Diego; Martínez Idrobo, Juan Pablo; Ceballos 
Sarria, Victoria Eugenia; Joaquí Daza, Samir Carlos y González Quijano, Dayan (2014), "Metodología para el análisis de vulnerabilidad en cuencas abastecedoras de agua ante la variabilidad climática", Revista Ingenierías Universidad de Medellín, 13 (25), Medellín, Universidad de Medellín, pp. 29-43, <https://bit.ly/ 39vol5J>, 23 de septiembre de 2021.

Vargas-Vargas Bryan (2020), "Perenne alerta roja: El modelo primario-exportador como generador y agravante de los conflictos socioambientales en Matina, Costa Rica (2000-2020)", tesis para obtener el título de especialización en Liderazgo, Cambio Climático y Ciudades, Facultad Latinoamericana de Ciencias Sociales, Quito, <https://bit. ly/3ilzwNm>.

Vargas-Vargas Bryan; Pacheco, Mónica; Rojas, Eduardo y Rojas, Tatiana (2015), "Distrito Curridabat: Renovación y Repoblamiento", conferencia presentada el 30 de septiembre de 2015, San José de Costa Rica, Posgrado de Arquitectura de la Universidad de Costa Rica, Facultad de Arquitectura, <https://bit. ly/2XLrkth>.

Welzer, Harald (2010), Guerras Climáticas. Por qué mataremos (y nos matarán) en el siglo XXI, Buenos Aires, Katzeditores.

Recibido: 23 de septiembre de 2021. Aceptado: 5 de noviembre de 2021. Publicado: 24 de enero de 2022.

\section{Bryan Vargas-Vargas}

Es master en Diseño Urbano por la Universidad de Costa Rica y estudia actualmente el Programa de Doctorado en Ciencias Sociales en la Universidad Nacional de Costa Rica. Es investigador del Centro Agenda Joven en Derechos y Ciudadanía de la Universidad Estatal a Distancia de Costa Rica. Sus líneas de investigación son juventud y estudios territoriales. Entre sus más recientes publicaciones destacan, como autor: "Integración curricular: articulación entre las instituciones educativas, los agentes locales y la ciudadanía joven de La Argentina de Pocora, Limón, Costa Rica", Territorios, núm. 44 (Esp.), Bogotá, Universidad del Rosario, pp. 1-21 (2021); "Micro-situaciones en el espacio público. Estudio de bulevares peatonales en San José, Costa Rica”, Arquitectura y Urbanismo, 41 (3), La Habana, Instituto Superior Politécnico José Antonio Echeverría, pp. 76-85 (2020); "La transformación de un barrio capitalino: la experiencia desde los y las residentes del barrio Escalante junto con el comercio gastronómico", Territorios, núm. 43, Bogotá, Universidad del Rosario, pp. 1-22 (2020); "Jóvenes centroamericanos: Una lectura desde los medios de comunicación escrita", Revista Rupturas, 10 (1), San José, Universidad Estatal a Distancia-Centro de Investigación en Cultura y Desarrollo, pp. 1-23 (2020). 